\title{
Severe Developmental Delay, Epilepsy and Neonatal Diabetes (DEND) Syndrome: A Case Report*
}

\author{
Muhd Alwi Muhd Helmi ${ }^{1}$ and Suhaimi Hussain ${ }^{2}$ \\ ${ }^{1}$ Paediatric Department, Kulliyyah of Medicine, International Islamic University Malaysia \\ ${ }^{2}$ Paediatric Department, School of Medical Sciences, University Sains Malaysia
}

\begin{abstract}
Developmental delay, Epilepsy and Neonatal Diabetes (DEND) syndrome is the most severe form of Permanent Neonatal Diabetes with KCNJ11 gene mutation which accounts for most of the cases. We report the first DEND syndrome in Malaysia with heterozygous missense mutation Q52R at KCNJ11 (Kir6.2) gene with delayed presentation beyond 6 months of age and failure to transition to glibenclamide. This report signifies the phenotypical variability among patients with the same genetic mutation and the different response to treatment.
\end{abstract}

Key words: DEND syndrome, glibenclamide, congenital diabetes

\section{INTRODUCTION}

Permanent Neonatal Diabetes Mellitus (PNDM) is defined as insulin-dependent diabetes with the onset of presentation in infant less than 6 months of age. ${ }^{1,2}$ There is a wide spectrum of neonatal diabetes with developmental delay, epilepsy and neonatal diabetes (DEND) syndrome being the most severe form within the spectrum. DEND syndrome is caused by gain of function mutation of either one of the proteins that made up the ATP-sensitive $\mathrm{K}+$ (K+ATP) channel, the pore-forming subunit (Kir6.2) or sulfonylurea receptor protein (SUR1). ${ }^{3}$ The Kir6.2 protein is encoded by KCNJ11 gene located at chromosome 11p15.1. ${ }^{4}$ The K+ATP channel is present in pancreatic $\beta$-cell, brain synapses and muscles. To date, there are at least $32 \mathrm{KCNJ11}$ gene mutations that can cause permanent neonatal diabetes. ${ }^{5}$ Most of these mutations occurred sporadically and involved single amino acid substitution due to missense or nonsense mutation. ${ }^{5,6}$ Among all, Q52R mutation has the most severe phenotype. ${ }^{3}$

In normal physiology, the $\mathrm{K}+\mathrm{ATP}$ channel will close in the presence of ATP. However, in DEND syndrome, the $\mathrm{K}+$ channel is persistently activated and remains open despite the presence of ATP. ${ }^{1}$ Sulfonylurea can bind to sulfonylurea receptor and inhibit the ATP-sensitive $\mathrm{K}+$ channel leading to its closure. This will trigger membrane depolarization that leads to the release of insulin., Due to this, sulfonylurea has been widely used in the management of patient with congenital diabetes to replace insulin. Patient with DEND syndrome that responded well to sulfonylurea showed improvement in the neurodevelopmental outcome. ${ }^{8,9}$
Here, we report the first case of DEND Syndrome in Malaysia due to Q52R single amino acid substitution mutation of KCNJ11 gene with late diagnosis beyond 6 months of age and failed transition from insulin to glibenclamide.

\section{CASE}

$\mathrm{ZH}$ is a Malay boy, the first child from non-consanguineous marriage. He was born at 41 weeks gestation via spontaneous vaginal delivery with birth weight $2500 \mathrm{~g}$ (below $10^{\text {th }}$ percentile), head circumference of $31 \mathrm{~cm}$ (below $3 \mathrm{rd}$ percentile) and length of $50 \mathrm{~cm}$ (at $50^{\text {th }}$ percentile). The antenatal period was uneventful. There was no maternal diabetes or hypertension, no polyhydramnios, reduced fetal movement or risk of sepsis throughout the pregnancy. Postnatally, he was well and was discharged home on the same day.

At 8-month old, $\mathrm{ZH}$ was referred to our hospital for severe Diabetic Ketoacidosis. He had hyperglycaemia with blood glucose level of $21 \mathrm{mmol} / \mathrm{L}$ and severe metabolic acidosis with blood $\mathrm{pH} 6.9$ and serum bicarbonate (HCO3-) level of $4.7 \mathrm{mmol} / \mathrm{L}$. He was ventilated for 48 hours for airway protection. The ketonemia and acidosis resolved after 24 hours of insulin infusion and hydration therapy. Insulin infusion was then converted to subcutaneous NPH human insulin $1 \mathrm{u}$ every 12 hours. The boy had two other past hospital admissions not related to diabetes. The first admission was for abdominal distention at the age of 3 months in which he was suspected to have possible Hirschsprung disease; while the second admission was at the age of 6 months for acute gastroenteritis.
ISSN 0857-1074 (Print) | eISSN 2308-118x (Online)

Printed in the Philippines

Copyright $(0) 2020$ by Helmi et al.

Received: October 10, 2019. Accepted: December 12, 2019.

Published online first: April 25, 2020.

https://doi.org/10.15605/jafes.035.01.22
Corresponding author: Suhaimi Hussain, MD

Consultant Paediatric Endocrinologist

Paediatric Department, Hospital University Sains Malaysia

Jalan Raja Perempuan Zainab II, Kubang Kerian

16150 Kota Bharu, Kelantan, Malaysia

Tel. No.: 6097673000

Fax No.: 6097671060

E-mail: hsuhaimi@gmail.com

ORCiD: https://orcid.org/0000-0002-7164-3076 
Initial investigation of diabetes revealed negative antiinsulin, anti-islet cells, anti-glutamic acid decarboxylase (anti-GAD) and anti-Islet Antigen 2 (anti-IA2) antibody with low C-peptide level. HbA1c was high at $16.5 \%$. Karyotyping was 46XY. Clinically, patient showed some facial dysmorphism with low set ears, micrognatia, short neck, and triangular mouth with thin lips. Other systemic examinations were unremarkable. The boy presented with global developmental delay: he had limited head control, he was not reaching for objects, he only smiled responsively, and just started vocalizing. With the clinical history, negative diabetes autoantibody, early onset of DM and the associated developmental delay, the boy was suspected to have DEND syndrome.

Since diagnosis, his development was globally arrested at around 4-6 months. Currently, at 5-years old, he has good head control but is still unable to roll over. His fine motor skills were significantly delayed since he is only able to reach for objects and bang 2 cubes. He is able to smile and laugh spontaneously, turn to loud sound and babble but does not respond to name-calling. There is no meaningful word except for monosyllables. On top of the developmental arrest, $\mathrm{ZH}$ also has poor linear growth. His latest height and head circumference were below the third percentile for age while his weight is at third percentile for age (Figure 1). He never had any seizure episodes. Electroencephalography (EEG) showed slowing of background wave with no epileptic discharges. The MRI brain showed normal brain structure. DNA sequence analysis to confirm the specific mutation causing the neonatal diabetes was sent to Exeter Clinical Laboratory when the child was two-and-a-half years old.

Heterozygous missense mutation Q52R was found at KCNJ11 (Kir6.2) gene at Exon 1 DNA. This missense mutation caused single amino acid substitution, Glutamine to Arginine at position 52 (p.Gln52Arg) of the protein. The genetic mutation together with severe global developmental delay and neonatal diabetes confirmed the diagnosis of DEND.

Switching of treatment from insulin to sulfonylurea was attempted at 3 years and 7 months old once the genetic diagnosis confirmed. The 'Inpatient Protocol for the Transfer of Patients with Kir6.2 and SUR1 Mutations from Insulin to Sulfonylurea in Patients with PNDM' developed by Prof Andrew Hattersley and team from University of Exeter was used as reference. ${ }^{10}$ In-patient low dose oral glibenclamide at $0.1 \mathrm{mg} / \mathrm{kg} /$ day was given in twice daily divided dose. Insulin was gradually weaned off whilst the glibenclamide dose was slowly escalated daily throughout 10 days to the maximum dose of $2 \mathrm{mg} / \mathrm{kg} /$ day. Regular 4 hourly post prandial capillary blood glucose monitoring was continued throughout his hospital stay. The blood sugar remained high despite an increasing dose of glibenclamide. At the dose of 2 $\mathrm{mg} / \mathrm{kg} /$ day, the patient developed diarrhea and became lethargic while the blood glucose level remained above $20 \mathrm{mmol} / \mathrm{L}$. Insulin was restarted and glibenclamide was then withheld. The side effects wore off. The repeat $\mathrm{HbA1c}$ was also increased compared to baseline during the trial period. At present, patient still has marked global developmental delay with $\mathrm{HbA} 1 \mathrm{c}$ of $7.1 \%$ and is on maintenance basal and prandial insulin.
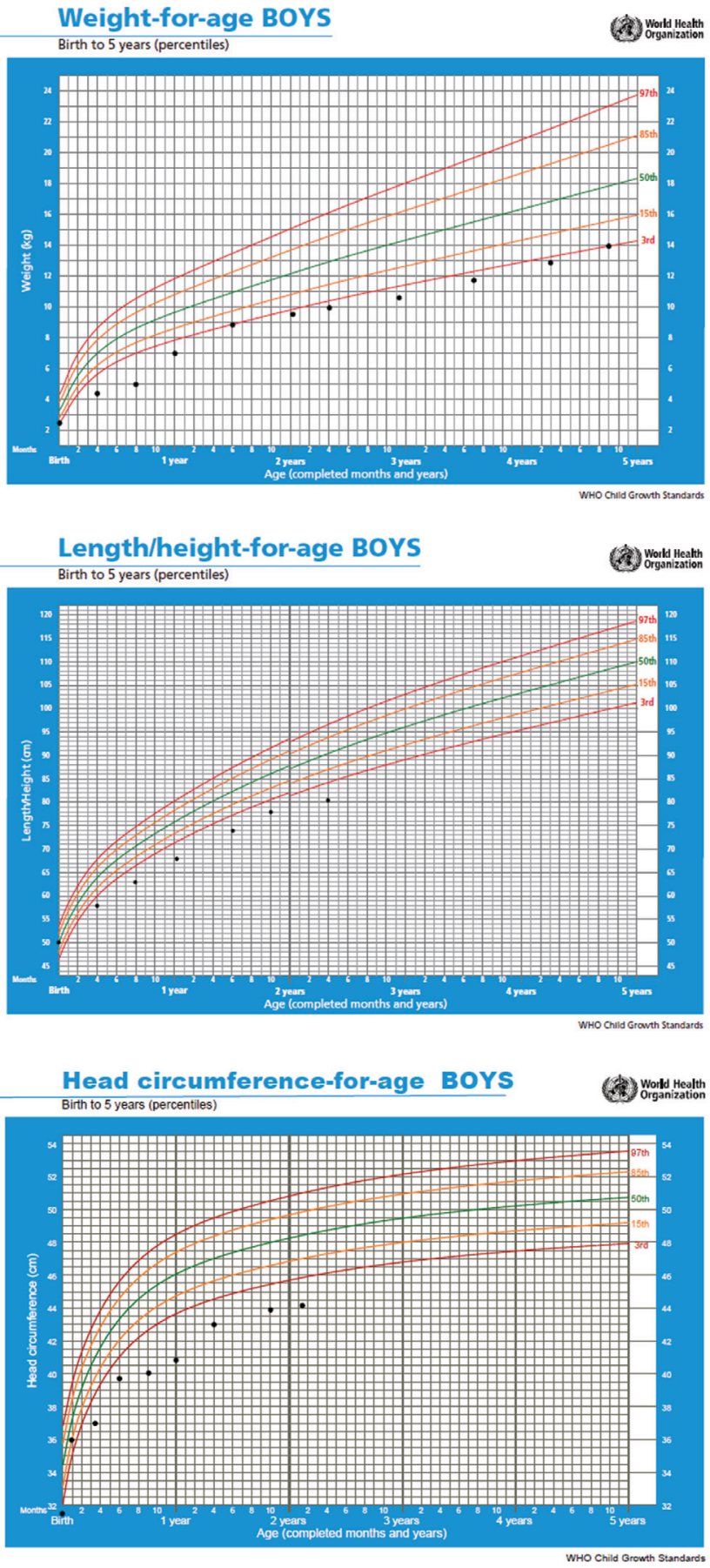

Figure 1. Weight, length and head circumference of $\mathrm{ZH}$. There was a poor linear growth noted from birth as plotted on WHO growth chart for weight, length and head circumference for age.

\section{DISCUSSION}

Based on our literature search up to this date, this is the first reported case of DEND Syndrome in Malaysia. Among all the mutations of the KCNJ11 gene that cause DEND syndrome, Q52R mutation has the worst clinical outcome. ${ }^{1,3}$ This particular mutation involves the substitution of amino acid Glutamine with Arginine at position 52 of the Kir6.2 protein. This leads to reduction in sensitivity of the channel to ATP without affecting its affinity. ${ }^{1,3}$ To date, there are 4 reported cases of patient with Q52R mutation. Among them, only 1 patient successfully 
switched from insulin to sulfonylurea, 1 patient partially responded to sulfonylurea but is still insulin dependent, while 1 patient died at infancy. All these patients first presented and were diagnosed under 6 months old (ranges 2 days to 4 months old) and all except for 1 had developmental delay and seizure at initial presentation. $\mathrm{ZH}$ was diagnosed with diabetes mellitus at the age of 8 months when he presented with DKA. No hyperglycemia was noted during the two earlier admissions. There are a few reported cases of patient with genetic mutation on either the Kir6.2 or the SUR1 protein who were diagnosed after 6 months of age.,11 However, the reason for the delayed presentation remains unexplained. ${ }^{3}$

Patients with this particular genetic mutation are known for sulfonylurea resistance and insulin dependency. ${ }^{12}$ Sulfonylurea works synergistically with ATP to close the $\mathrm{K}$ channel. The former inhibitory action can only exert its full effect if the Kir6.2 protein sensitivity to ATP is intact. Therefore, in patients with Q52R mutation, the substitution of Glutamine by Arginine at distal position of the protein alters the structure of the pore of the protein leads to insensitivity of the channel to ATP binding. ${ }^{8}$ This partially explains the failure to respond to sulfonylurea therapy in this patient. Even though there are reported cases of successful sulfonylurea therapy in patients with Q52R mutation, this phenomenon is to date not fully explained and might represent the variability of expression within the same genetic mutation. ${ }^{8}$

Other factors leading to failure of insulin replacement include low birth weight and delay in introduction of sulfonylurea. ${ }^{12}$ In this case, $\mathrm{ZH}$ had birth weight below $10^{\text {th }}$ percentile and sulfonylurea was introduced rather late at the age of 3 years and 7 months old due to the delay in the confirmation of genetic mutation. In a case report, Greeley et al, 2016 reported that the number of $\beta$-cells in a 2-year-old female with KCNJ11 mutation was significantly less compared to normal age-matched children. ${ }^{13}$ Over time, there is a reduction in $\beta$-cell numbers in the pancreas of patients with KCNJ11 mutation DEND syndrome that might explain the inverse proportion of successful transition with age and the need for a higher dose of sulfonylurea. ${ }^{3}$ The only patient successfully treated with glibenclamide monotherapy was given glibenclamide $2.6 \mathrm{mg} / \mathrm{kg} /$ day in $4-8$ divided doses. However, since glibenclamide has a half-life between 12 to 24 hours with peak concentration achieved in 2 to 4 hours post ingestion, giving 12 hourly of high dose glibenclamide should exert optimal effect. ${ }^{14}$ In our case, increasing frequency of glibenclamide dosing may be beneficial. However, since our patient was unable to tolerate the high dose of glibenclamide, this is not an option.

\section{CONCLUSION}

In conclusion, this case report describes the variability of presentation in patients with the same genetic mutation and the challenges in managing DEND syndrome patients with severe genetic mutation such as Q52R mutation. Prompt genetic analysis is vital to avoid delay in diagnosis and trial of glibenclamide therapy. The transition to sulfonylurea from insulin should be the main aim in the treatment of patients with DEND syndrome as it may reverse neurodevelopmental delay and seizure. Since patients with KCNJ11 mutation require high doses of glibenclamide, newer drugs with similar modes of action but with better side effect profiles may be alternative therapy for this population of patient. However, more studies are required to prove this hypothesis.

\section{Acknowledgments}

The authors would like to thank Dr. Sarah Flanagan for her contribution in performing DNA sequence analysis for our patient. Dr. Eva Foong, genetic pathology trainee, Hospital University Sains Malaysia for her input on genetic information of the described patient and genetic consultation. They would also like to thank Associate Professor Dr. Salmi Abd Razak, paediatric neurologist, Hospital University Sains Malaysia for performing and reporting the patient's electroencephalogram and managing the patient's seizure and developmental delay. Finally, they would like to show their gratitude to Mrs. Noraida Hassan and Mrs. Nurul Azurah Mohd Roni for their tutorial and help in the referencing process using Endnote.

\section{Ethical Consideration}

Patient consent was obtained before submission of the manuscript.

\section{Statement of Authorship}

All authors certified fulfillment of ICMJE authorship criteria.

\section{Author Disclosure}

The authors declared no conflict of interest.

\section{Funding Source}

None.

\section{References}

1. Koster JC, Kurata HT, Enkvetchakul D, Nichols CG. DEND mutation in Kir6. 2 (KCNJ11) reveals a flexible N-terminal region critical for ATP-sensing of the KATP channel. Biophys J. 2008;95(10):4689-97. PMID: 18708460. PMCID: PMC2576385. https://doi.org/10.1529/ biophysj.108.138685.

2. Stanik J, Gasperikova D, Paskova M, et al. Prevalence of permanent neonatal diabetes in Slovakia and successful replacement of insulin with sulfonylurea therapy in KCNJ11 and ABCC8 mutation carriers. J Clin Endocrinol Metab. 2007;92(4):1276-82. PMID: 17213273. https:// doi.org/10.1210/jc.2006-2490.

3. Ashcroft FM, Puljung MC, Vedovato N. Neonatal diabetes and the KATP channel: From mutation to therapy. Trends Endocrinol Metab. 2017;28(5):377-87. PMID: 28262438. PMCID: PMC5582192. https://doi. org/10.1016/j.tem.2017.02.003.

4. Souza SW, Alcazar LP, Arakaki P, et al. Polymorphism E23K (rs5219) in the KCNJ11 gene in Euro-Brazilian subjects with type 1 and 2 diabetes. Genet Mol Res. 2017;16. PMID: 28387875. https://doi.org/10.4238/ gmr16029543.

5. Stenson PD, Mort M, Ball EV, Shaw K, Phillips AD, Cooper DN. The human gene mutation database: Building a comprehensive mutation repository for clinical and molecular genetics, diagnostic testing and personalized genomic medicine. Hum Gen. 2014;133(1):1-9. PMID: 24077912. PMCID: PMC3898141. https://doi.org/10.1007/s00439-0131358-4.

6. Flanagan SE, Clauin S, Bellanné-Chantelot C, et al. Update of mutations in the genes encoding the pancreatic beta-cell K(ATP) channel subunits Kir6.2 (KCNJ11) and sulfonylurea receptor 1 (ABCC8) in diabetes mellitus and hyperinsulinism. Hum Mutat. 2009;30(2): 170-80. PMID: 18767144. https://doi.org/10.1002/humu.20838.

7. Shimomura K, Maejima Y. KATP channel mutations and neonatal diabetes. Intern Med. 2017;56(18):2387-93. PMID: 28824061. PMCID: PMC5643163. https://doi.org/10.2169/internalmedicine.8454-16.

8. Ioacara S, Flanagan S, Fröhlich-Reiterer E, Goland R, Fica S. First case of neonatal diabetes with KCNJ11 Q52R mutation successfully switched from insulin to sulphonylurea treatment. J Diab Investig. 2017;8(5):716-9. PMID: 28083968. PMCID: PMC5583959. https://doi. org/10.1111/jdi.12620.

9. Singh P, Rao SC, Parikh R. Neonatal diabetes with intractable epilepsy: DEND syndrome. Indian J Pediatr. 2014;81(12):1387-8. PMID: 24912436. https://doi.org/10.1007/s12098-014-1486-4.

10. Hattersley A. Inpatient protocol for the transfer of patients with Kir6.2 and SUR1 mutations from insulin to sulphonylureas in patients with PNDM [Treatment protocol ]. Unpublished. 
11. Rubio-Cabezas O, Flanagan SE, Damhuis A, Hattersley AT, Ellard S. KATP channel mutations in infants with permanent diabetes diagnosed after 6 months of life. Pediatr Diabetes. 2012;13(4):322-5. PMID: 21981029. https://doi.org/10.1111/j.1399-5448.2011.00824.x.

12. Heo JW, Kim SW, Cho EH. Unsuccessful switch from insulin to sulfonylurea therapy in permanent neonatal diabetes mellitus due to an R201H mutation in the KCNJ11 gene: A case report. Diabetes Res Clin Pract. 2013;100(1):e1-2. PMID: 23434183. https://doi.org/10.1016/j. diabres.2013.01.016
13. Greeley SAW, Zielinski MC, Poudel A, et al. Preservation of reduced numbers of insulin-positive cells in sulfonylurea-unresponsive KCNJ11-related diabetes. J Clin Endocrinol Metab. 2017;102(1):1-5 PMID: 27802092. PMCID: PMC5413092. https://doi.org/10.1210/ jc.2016-2826.

14. Bösenberg LH, van ZylDG. The mechanism of action of oral antidiabetic drugs: A review of recent literature. JEMDSA. 2008;13(3):80-8. https://doi.org/10.1080/22201009.2008.10872177.

Authors are required to accomplish, sign and submit scanned copies of the JAFES Author Form consisting of: (1) Authorship Certification, that authors contributed substantially to the work, that the manuscript has been read and approved by all authors, and that the requirements for authorship have been met by each author; (2) the Author Declaration, that the article represents original material that is not being considered for publication or has not been published or accepted for publication elsewhere, that the article does not infringe or violate any copyrights or intellectual property rights, and that no references have been made to predatory/ suspected predatory journals; (3) the Author Contribution Disclosure, which lists the specific contributions of authors; and (4) the Author Publishing Agreement which retains author copyright, grants publishing and distribution rights to JAFES, and allows JAFES to apply and enforce an Attribution-Non-Commercial Creative Commons user license. Authors are also required to accomplish, sign, and submit the signed ICMJE form for Disclosure of Potential Conflicts of Interest. For original articles, authors are required to submit a scanned copy of the Ethics Review Approval of their research as well as registration in trial registries as appropriate. For manuscripts reporting data from studies involving animals, authors are required to submit a scanned copy of the Institutional Animal Care and Use Committee approval. For Case Reports or Series, and Images in Endocrinology, consent forms, are required for the publication of information about patients; otherwise, appropriate ethical clearance has been obtained from the institutional review board. Articles and any other material published in the JAFES represent the work of the author(s) and should not be construed to reflect the opinions of the Editors or the Publisher.

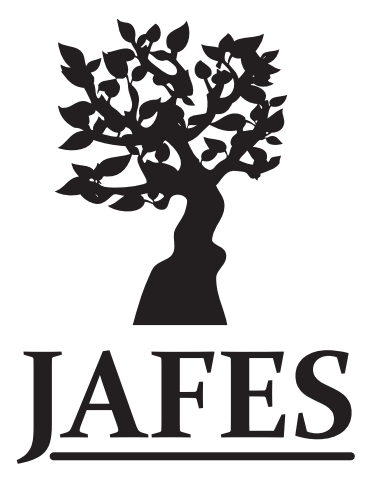

Experience the new JAFES.

Visit us at www.ASEAN-endocrinejournal.org. 